\title{
Analysis and study of vibrations in view of combustion gas forces for diesel engine
}

\author{
Sushant S.Bhansali ${ }^{1}$, Dr. U.V.Kongre ${ }^{2}$, N.D.Shirgire ${ }^{3}$, P.R.Bodade ${ }^{4}$ \\ ${ }_{1,2,3,4}$ (Department of Mechanical Engg./ J.D.I.E.T., Yavatmal (M.S.)/ Amravati University, India)
}

\begin{abstract}
The sound and vibratory behavior of the internal combustion engine is a highly complex one, consisting of many components that are subject to loads that vary greatly in magnitude and which operate at a wide range of speeds. Some origins of mechanically induced noise caused by various forces resulting from the combination of combustion and inertia forces which act on the moving parts of the engine to accelerate them across their running clearances and thus cause mechanical noise. The most of the investigations are done on the mechanical noise due to motion of mechanical system i.e. piston slap. The main purpose of this work is to analyze the vibration in diesel engine VCR (Variable Compression Ratio) cylinder liner considering combustion gas forces and cylinder liner temperature using finite element software ANSYS. Also Aluminium (HF 18) material is being tested in the software for this purpose. The output results were quite satisfactory to predict the behavior of deflection under different pressures. The combustion gas forces calculated for varying compression pressures. In this paper the results are presented for displacement and frequency which indicate the amplitude of vibration. By comparing the analytical results, the validity of the proposed analysis has been confirmed. Furthermore, this analysis is applied to evaluate the vibration of HF 18 material along with increase in thickness, and revealing the closer response according to the material and vibration.
\end{abstract}

Keywords - VCR Diesel engine, Cylinder liner, Combustion gas force and Harmonic analysis.

\section{Introduction}

Recently, a demand to the silence in the automobiles is increasing and the strengthening of the traffic noise regulations are carrying out. Thus the reduction of engine noise as the dominant source of vehicle noise is imperative. Some origins of mechanically induced noise caused by various forces (resulting from combination of combustion and inertia forces) which act on the moving parts of the engine to accelerate them across their running clearances and thus cause mechanical impacts. These impacts are found to be the main cause of predominant high frequency noise. Engine noise is divided roughly into two types. One is combustion noise, which originates from the combustion gas pressure in the cylinder, and other is mechanical noise, which arises due to the motion of the mechanical system i.e. piston slap impacts and other mechanical impacts in gears and bearings. Especially, the bearing noise imparted by impact and vibration caused by fluctuating forces due to various mechanisms during the engine cycle. Piston slap is a collision phenomenon between the piston and the cylinder liner when the lateral force acting on the reciprocating piston. As a result piston slap was identified and the instants of slap were determined. These were compared with the instants of slap calculated from a theoretical analysis of the dynamics of the moving parts of the engine [1]. Another investigation presented the various methods for estimating the pistons slap. This phenomenon of piston slap has been investigated by oscillographic and simulation technique to determine its relative magnitude, compared with the other noise sources of the engine. It has been found that this source of noise is important and its significance will become greater as other sources, such as combustion are reduced [2]. The finite element method (FEM) is employed to simulate the vibration response of the hull due to the excitations of diesel piston-slap and vertical inertia force of reciprocating masses. The numerical results show that, piston-slap imposed rolling moment on the diesel frame may cause a higher level vibration $[3,4,5]$. In an analytical model, predict the impact forces and vibratory response of engine block surface induced by the piston slap of an internal combustion engine. When slap occurs, the impact point between piston skirt and cylinder inner wall is modeled on a two-degree-of-freedom vibratory system. The equivalent parameters such as mass, spring constant and damping constant of piston and cylinder inner wall are estimated by using measured (driving) point mobility [6]. In this paper, modeling was done at the cross section of engine cylinder liner including 2-dimensional and 3-dimensional analysis. Beam and 3dimensional liner are consisting of thickness of cylinder and stroke length of cylinder. The results are considered for calculating the combustion forces for the certain ranges of compression pressure (between 45-75bar). Further, the effect of cylinder liner temperature was also analyzed.

\section{Generation of engine noise vibration related to piston slap}

Looking towards the threat of vibration which is hazardous which may lead the total failure of the systems need to addressed. From few research efforts continuously focus their attention towards vibration or 
deflection analysis from different means which further causes the depth in analysis of vibration considering combustion gas force. In this work comparatively higher pressure zones were analyzed to understand the vibration behaviors of the engine. It imparts different material analysis with or without additional thickness to view the vibration with different aspects. Most of the researchers have found for the mechanical noise i.e. piston slap. The noise due to combustion gas force is the major source for the occurrence of noise in the engine cylinder. Very few efforts are devoted for combustion gas force analysis. Little attention was paid on noise and vibration due to combustion gas force. The work focuses on vibration issue and the main causes of mechanical noise are the "piston slap" phenomenon [3-5, 7]. The Problem is formulated as under study of the cross section of engine cylinder liner as 2-dimensional and 3-dimensional model with the help of ANSYS Version 10. Beam and 3-dimensional liner are consisting of thickness of cylinder and stroke length of cylinder. In this analysis, application of combustion gas forces and cylinder liner temperature on the piston cylinder components to investigate the vibration. The problem is described in a two dimensional beam and three dimensional model along with model meshing as shown in figure 2.1 and figure 2.2. Calculating combustion gas forces for the certain peal ranges of compression pressure (between 45-75 bar), considering cylinder liner temperature [8].

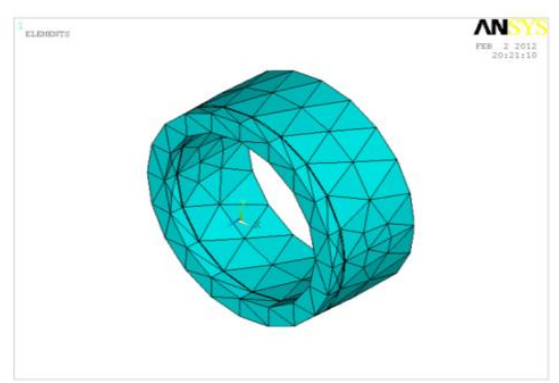

Fig. 2.1: 3-Dimensional Model Meshing

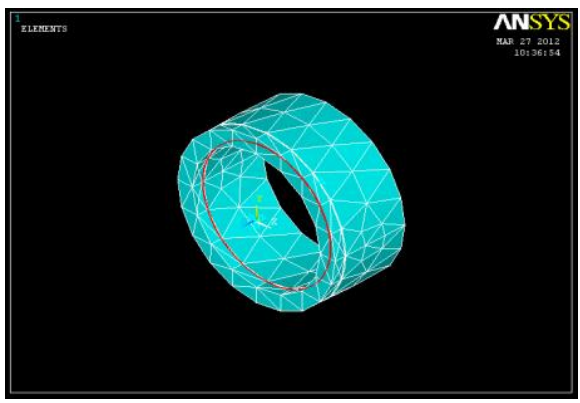

Fig. 2.2: Combustion Gas Forces in 3-Dimensional Model after Meshing

In order to simulate the model, prerequisites are as follows,

- Geometry: - Cross section of engine cylinder as a 2-D and 3-D model with the help of ANSYS.

- Boundary Conditions: - By fixing left side of model as all DOF zero and fixing the right side of model as UX as zero.

- Mesh: - Mapped (3-4 sided).

- Force Analysis: - Combustion gas forces applied at TDC position only.

- Parameters: - Analysis was done from nodal solution and graph.

- Analysis Method:- Harmonic Analysis

For the geometry analysis the work includes single cylinder, four stroke, and VCR (Variable Compression Ratio) Diesel engine. The specifications of engine are as shown in table 2.1. In dealing with this there are some basic assumptions that need to be addressed.

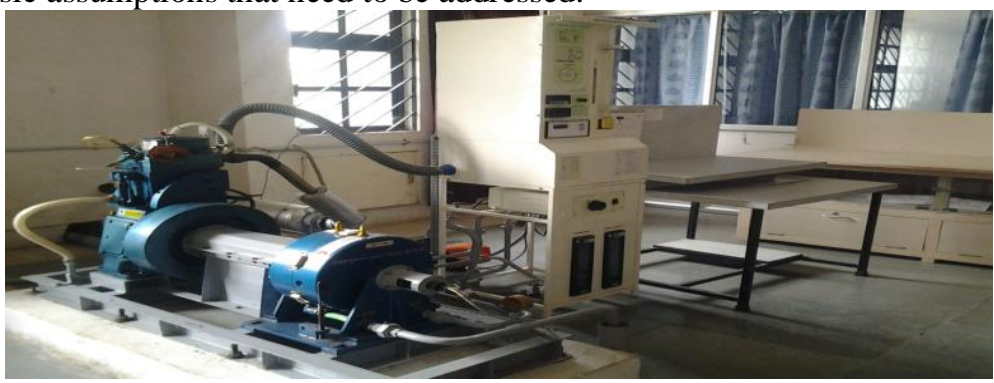

Fig 2.3: Figure showing single cylinder, four stroke, and VCR (Variable Compression Ratio) Diesel engine

Table 2.1: Specifications of Diesel Engine [11]

\begin{tabular}{|l|l|}
\hline Features & Specifications \\
\hline Model & TV1 \\
\hline Make & Kirloskar oil Engine \\
\hline Type & Four stroke, Water cooled Diesel \\
\hline No. of cylinder & One \\
\hline Combustion Principle & Compression ignition \\
\hline Max speed & $2000 \mathrm{rpm}$ \\
\hline
\end{tabular}


Analysis and study of vibrations in view of combustion gas forces for diesel engine

\begin{tabular}{|l|l|}
\hline Min speed & $750 \mathrm{rpm}$ \\
\hline Min operating speed & $1200 \mathrm{rpm}$ \\
\hline Crank Radius & $39.5 \mathrm{~mm}$ \\
\hline Connecting Rod length & $234 \mathrm{~mm}$ \\
\hline Cylinder diameter & $87.5 \mathrm{~mm}$ \\
\hline Thickness of cylinder & $10 \mathrm{~mm}$ \\
\hline Piston diameter & $87.44 \mathrm{~mm}$ \\
\hline Compression ratio & $17.5: 1$ \\
\hline Material of cylinder & Grey cast iron \\
\hline Stroke length & $110 \mathrm{~mm}$ \\
\hline Cut off ratio at 2000rpm & 2.5 \\
\hline
\end{tabular}

\subsection{Assumptions}

i. The piston contacts the cylinder bore at the top and bottom of the piston skirt.

ii. $\quad$ Piston skirt deformation and linear elasticity are considered negligible.

iii. The skirt/liner oil film exhibits little effect on the transverse motion of the piston.

iv. Take the range of Compression pressure as 45, 50, 55, 60, 65, 70, 75 bar. And from that pressure calculate the combustion gas force.

v. The gas forces are assumed to act through the centre line of the piston so that the equations of motion apply no matter where the piston is in the cylinder.

vi. Behaviour of gases is considered close to ideal gases.

vii. Pressure developed after compression is calculated on the basis of assumption that compression process is following isentropic.

\subsection{Calculation of Gas forces}

Calculation of gas forces were carried out to define the compression pressure during combustion in an engine. Following are the calculations performed for featured analysis of vibration due to combustion gas force. Force acting due to gas pressure on piston

Force $=\mathrm{P} * \Pi / 4 * \mathrm{~d}_{\mathrm{p}}{ }^{2}$

Where, $\mathrm{P}=$ Compression Pressure

$\mathrm{d}_{\mathrm{p}}=$ Piston Diameter

\section{Modelling and Simulation}

Simulation technique can never be complete replacement for an experimental testing. But they can provide a useful service in that the effect of parameter changes may readily be expressed without resource cutting metal, leaving experiment to confirmatory role. Experiment must also provide the evidence needed to validate the mathematical model in first instance. Since, vibration characteristic can be found with empirical relations it is also helpful to get the point load that impact on the side of the cylinder, data was taken from books, which were used to run the program. The studied system representing an I.C. combustion engine is modeled as a cylinder liner which is consisting of cylinder thickness and stroke length. Simulation with the finite element software ANSYS lends to the integration to the piston and cylinder liner. Finite element models were created based on the geometry of the system assembly. The modeling and simulation was carried out using the finite element software ANSYS [12]. For the problem use was made of a two dimensional beam and 3dimensional cylinder liner. A job was created with its attendant job name. I the pre-processor domain, modeling was picked and then area selected to create the job dimensions.

In element type regions the pre-processor for selecting the element type for 2-D (plane 42) and for 3-D (Solid 45). The type of material and its properties were chosen in the material properties -material models for solid. An element size edge of 0.001 was used to mesh the model. This was done signifying the default attribute and the plane 42 and Solid 45 with the material model1. Plane 42 is selected to mesh a plane in 2-dimensional beam and solid 45 is selected to mesh a plane in 3-dimension model. Also apply the reference cylinder liner temperature $473 \mathrm{~K}[9]$.

Table 3.1 Properties of Material [10]

\begin{tabular}{|l|l|l|l|l|}
\hline \multicolumn{2}{|l|}{ Material name } & $\begin{array}{l}\text { Modulus of } \\
\text { elasticity }\end{array}$ & Poison's ratio & Density \\
\hline Aluminum & 22588(HF18) & 90000 & 0.3 & 2700 \\
\hline
\end{tabular}




\subsection{Harmonic Analysis for 2-Dimensional Beam (Cylinder Liner)}

Harmonic analysis deals with the response of structure to harmonically time varying loads. It gives the ability to predict the sustained dynamic behavior of structure. While the steady state deals with point loads the harmonic analysis deals with varying loads with frequency. For actuating the harmonic analysis, the meshing of 2D beam were completed to process further analysis of the work. It includes entering into solution and to select proper harmonic analysis. Choosing Full solution method and selecting the Frontal solver. In this work the damping ratio $2 \%$ for vibration or deflection analysis. Apply boundary conditions, by selecting the define load, by selecting the displacement from structural, as fix the left side of beam (cylinder liner) as all DOF zero and fix the right side of beam as UX zero. Selecting the force / moment, apply the combustion gas force at TDC of cylinder liner and also apply gravity force.

\section{For the material HF 18 for 2-D}

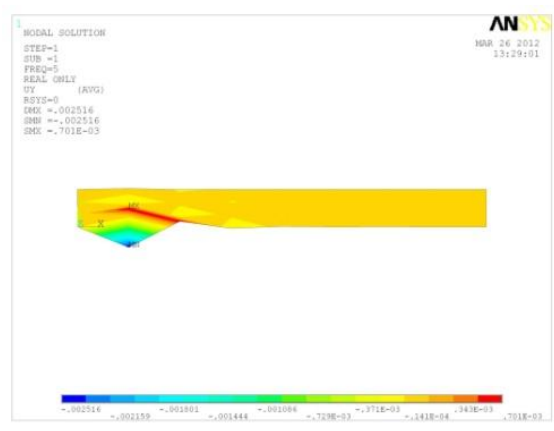

Fig3.1.1: Nodal solution for 45 bar compression pressure

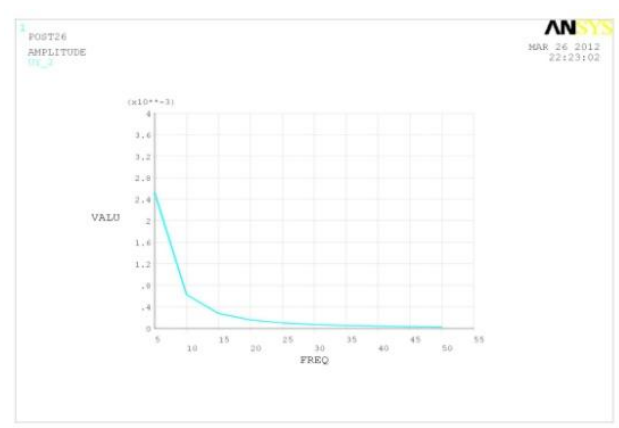

Fig3.1.2: Graph for 45 bar pressure

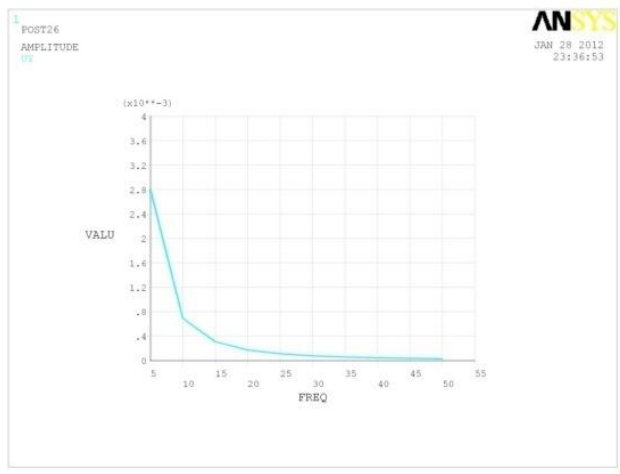

Fig3.1.4: Graph for 50bar pressure

Fig3.1.6: Graph for 55 bar

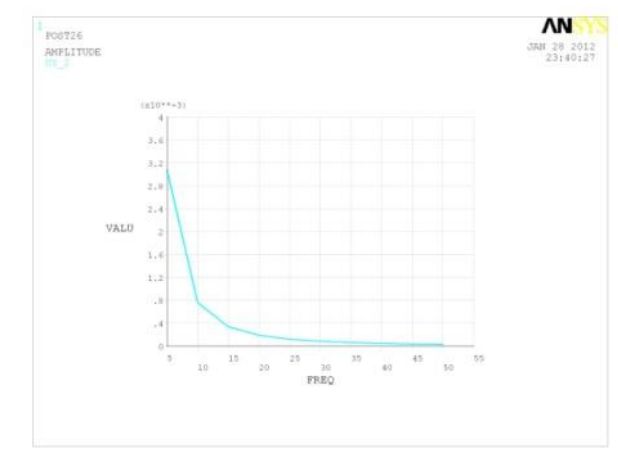

Fig3.1.5: Nodal solution for 55 bar compression pressure

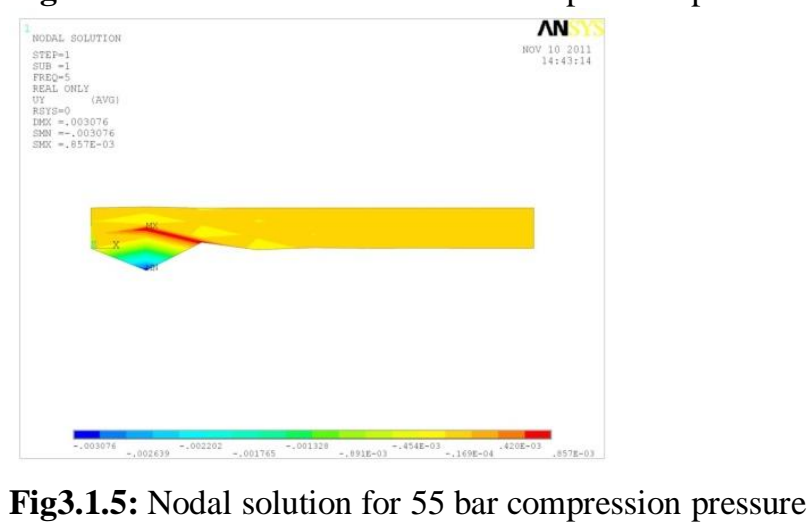




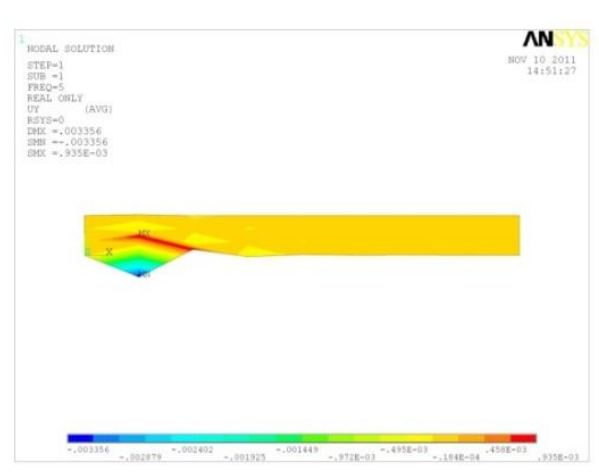

Fig3.1.7: Nodal solution for 60 bar compression pressure

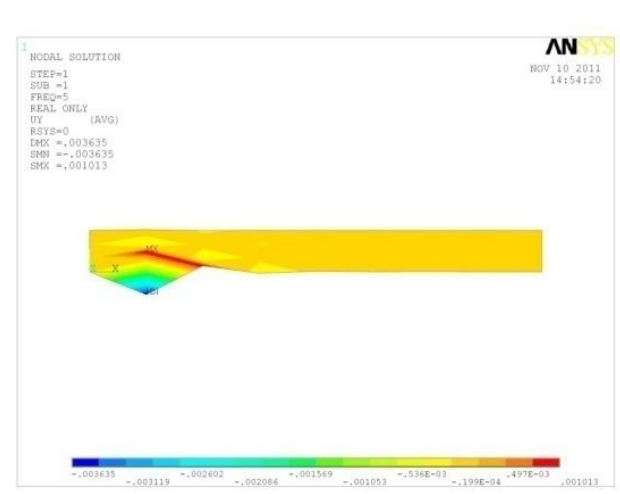

Fig3.1.9: Nodal solution for 65 bar compression pressure

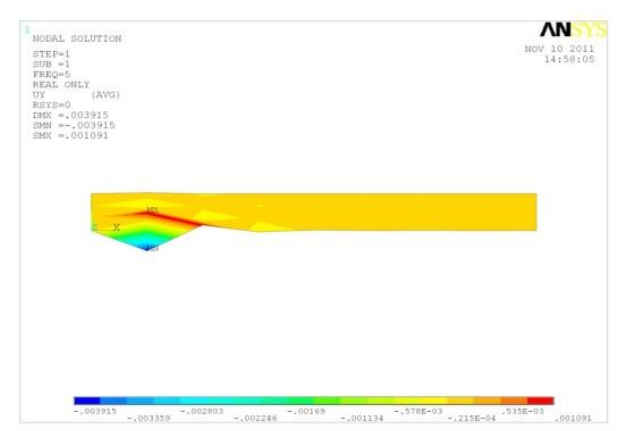

Fig3.1.11: Nodal solution for 70 bar compression pressure

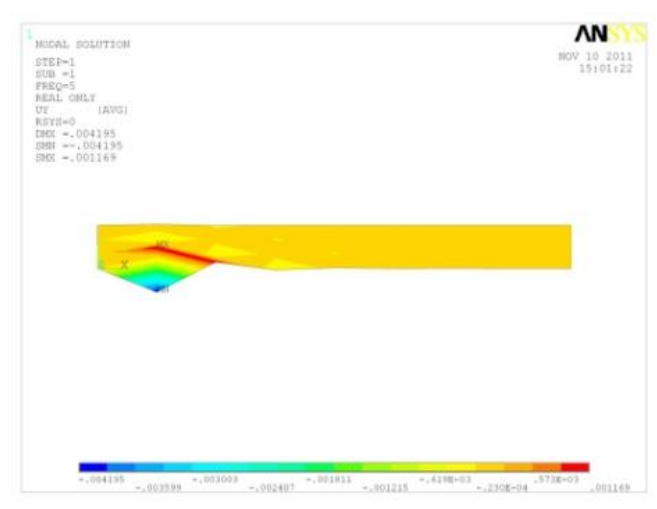

Fig3.1.13: Nodal solution for 75 bar compression pressure

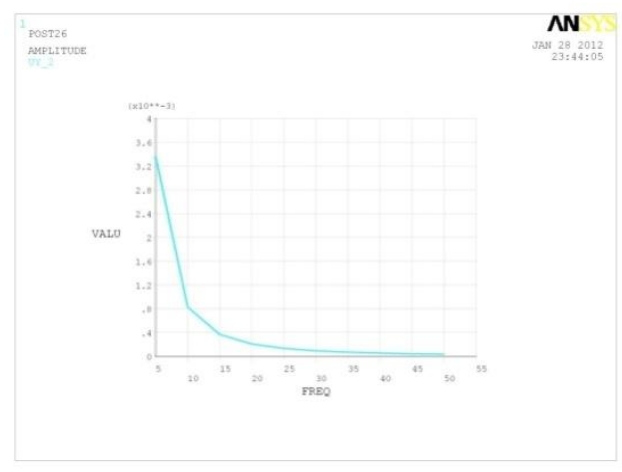

Fig3.1.8: Graph for 60bar pressure

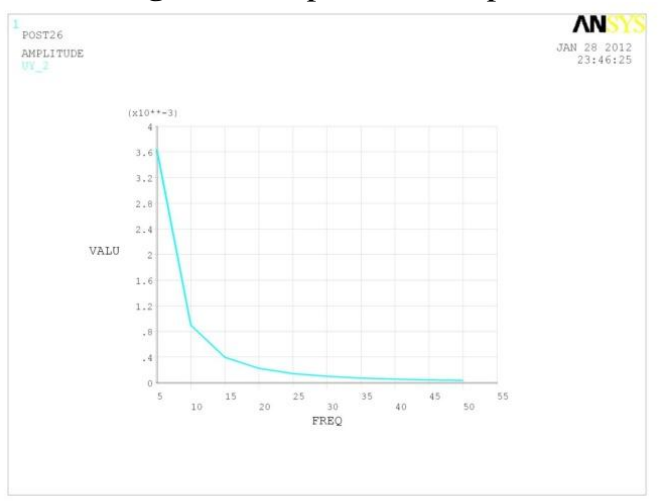

Fig3.1.10: Graph 65 bar Pressure

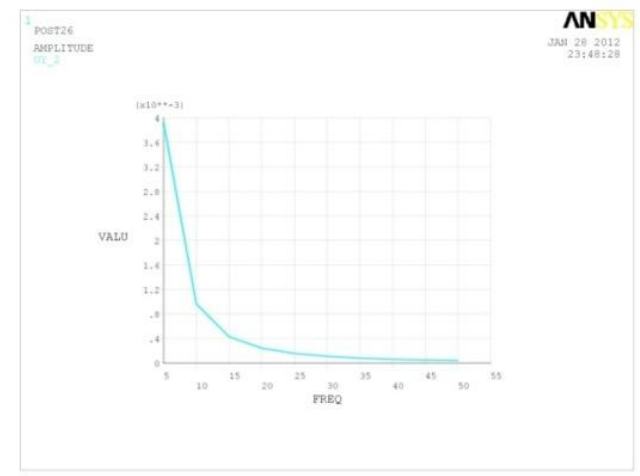

Fig3.1.12: Graph for 70bar pressure

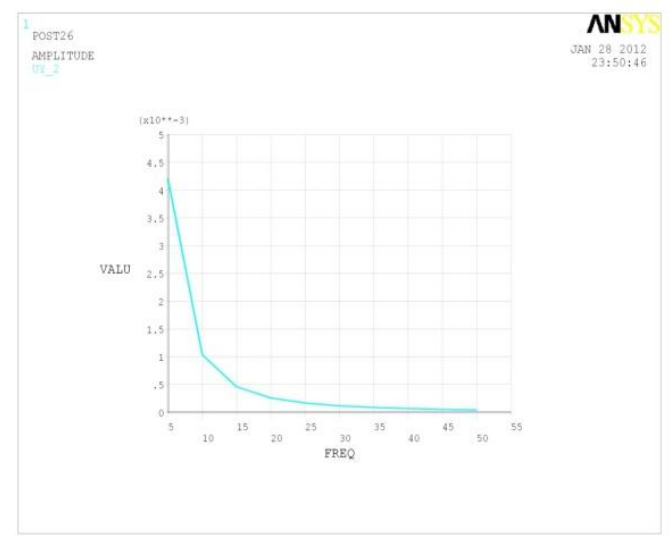

Fig8.3.14: Graph for 75bar pressure

\subsection{Harmonic Analysis for 3-Dimensional Model (Cylinder Liner)}

For 3-dimensional model, drawing the two concentric circles, considering the thickness and diameter of cylinder and extrudes the same. After extruding, mesh the models. And start the harmonic analysis. In harmonic 
analysis, repeat the procedure as in 2-D up to boundary conditions. Instead of applying the combustion gas force, apply only compression pressure to 3D model. After that, repeat the same procedure as in $2 \mathrm{D}$ for getting nodal solutions. 3D model can deflect in two directions i.e. in Y and Z-direction. The output results of harmonic analysis are created using ANSYS on 3D model for all types compression pressures.

\section{Results and Discussion}

This work describes the results obtained after the analysis which includes HF 18 material along with the directions. After applying gas forces to 2-dimensional and 3-dimensional cylinder liner, we get some results. In this chapter we discuss the node number at which we get the deflection due to each compression pressure. In following table, at node 22, the 2-dimensional beam deflects in Y direction due to combustion gas force.

Table 4.1: Nodes at which 2-Dimensional beam Deflects in Y direction

\begin{tabular}{|c|c|}
\hline Compression pressure / Property & $\begin{array}{c}\mathbf{2 2 5 8 8 ( H F ~ 1 8 )} \\
\text { (Aluminum) }\end{array}$ \\
\hline 45bar & $0.25161 \mathrm{E}-02$ \\
\hline 50bar & $0.27965 \mathrm{E}-02$ \\
\hline 55bar & $0.30762 \mathrm{E}-02$ \\
\hline 60bar & $0.33558 \mathrm{E}-02$ \\
\hline 65bar & $0.36355 \mathrm{E}-02$ \\
\hline 70bar & $0.39151 \mathrm{E}-02$ \\
\hline 75bar & $0.41948 \mathrm{E}-02$ \\
\hline
\end{tabular}

22588(HF 18) (Aluminum)

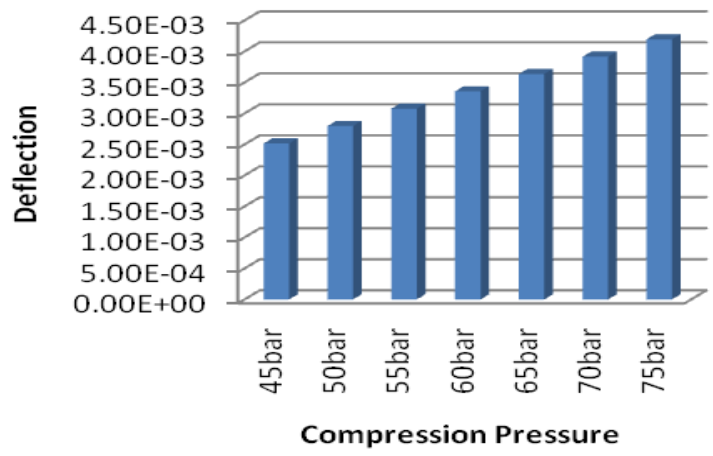

22588(HF 18)

(Aluminum)

Fig.4.1: Compression Pressure vs. Deflection for 2D

From above figure at 45 bar compression pressure the minimum value of deflection and the maximum deflection value at 75 bar pressure for the material aluminium (HF-18). The 3-dimensional model deflects in $\mathrm{Y}$ as well as in Z-direction due to combustion gas force. Firstly discuss the deflection in Y-direction. In following table, at node 158, the 3-dimensional beam deflects in $\mathrm{Y}$ direction due to combustion gas force.

Table 4.2: Nodes at which 3-Dimensional Model Deflects in Y direction

\begin{tabular}{|c|c|}
\hline Compression pressure / Property & $\begin{array}{c}\text { 22588(HF 18) } \\
\text { (Aluminum) }\end{array}$ \\
\hline 45bar & $0.97098 \mathrm{E}-05$ \\
\hline 50bar & $0.10789 \mathrm{E}-04$ \\
\hline 55bar & $0.11867 \mathrm{E}-04$ \\
\hline 60bar & $0.12946 \mathrm{E}-04$ \\
\hline 65bar & $0.14025 \mathrm{E}-04$ \\
\hline 70bar & $0.15104 \mathrm{E}-04$ \\
\hline 75bar & $0.16183 \mathrm{E}-04$ \\
\hline
\end{tabular}




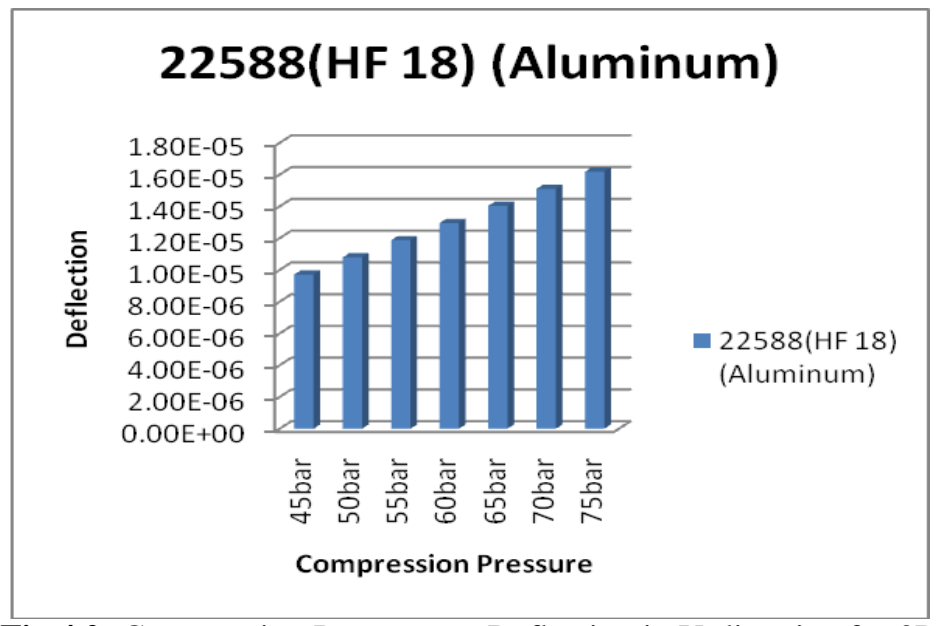

Fig.4.2: Compression Pressure vs. Deflection in Y-direction for 3D

From above figure it is seen that, at 45 bar pressure the minimum value of deflection and the maximum values of deflection at 75 bar pressure. In following table, the 3-dimensional model deflects in $\mathrm{Z}$ direction at node 109 due to combustion gas force.

Table 4.3: Nodes at which 3-Dimensional Model Deflects in $\mathrm{Z}$ direction

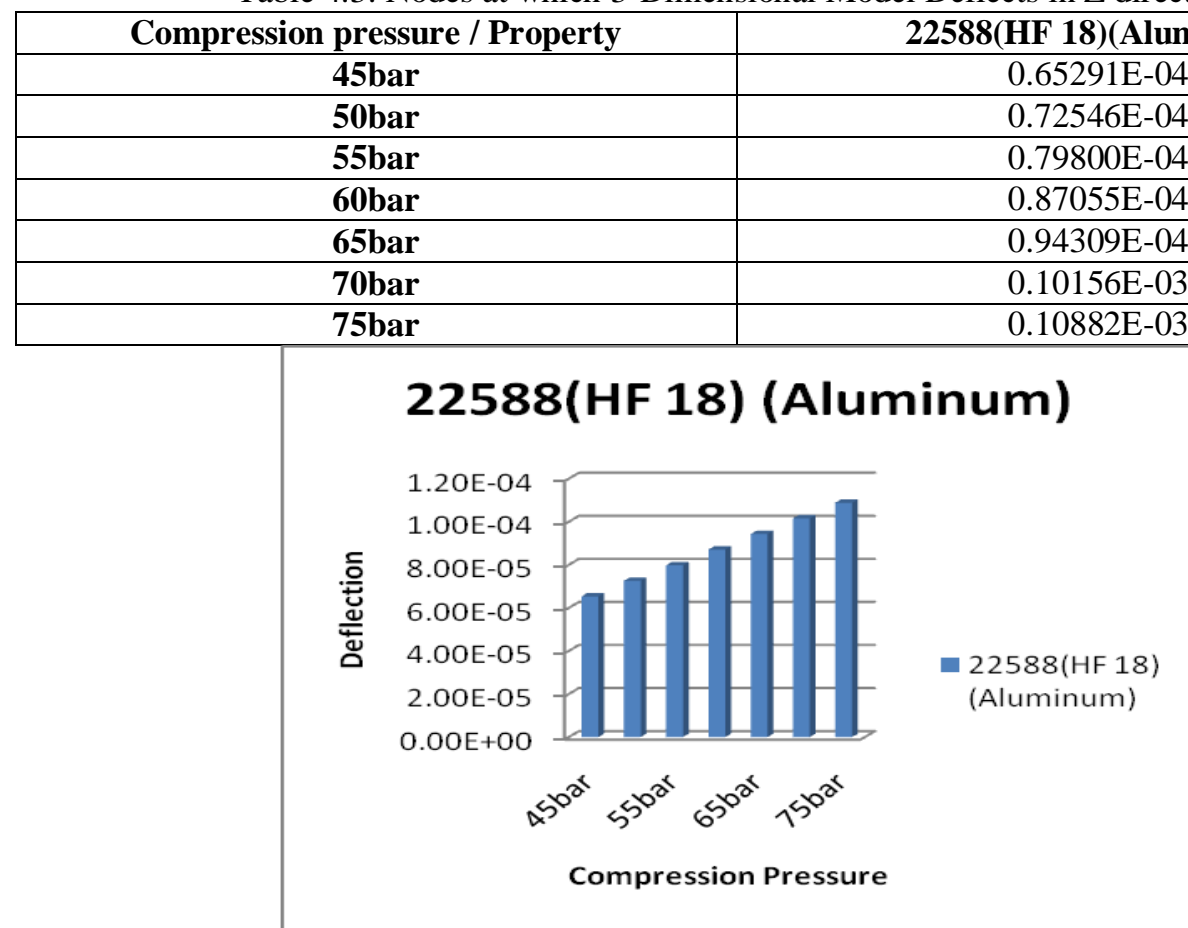

Fig.4.3: Compression pressure vs. Deflection for 3D

\subsection{Reduction of Vibration}

In this work, second major part undertaken to reduce the vibration with design point of view. In addition to this it is proposed from theoretical findings from the analysis that if we add $1 \mathrm{~mm}$ thickness of cylinder from outer periphery, we obtained better result for reduction in vibration. Thus to reduce the vibration in diesel engine due to combustion gas forces by optimization method through increasing the thickness of cylinder by $1 \mathrm{~mm}$ found better and the same results were demonstrated by the analysis. Some of the results of 2-dimensional beam HF 18 are shown, vibration get reduced as compared to the conventional thickness of cylinder. Also same results were found for 3-dimensional model. ANSYS-10 version was utilized for post processing the results which are applied for 2-dimensional and 3-dimensional analysis. The results demonstrated by ANSYS were detailed discuss with reference to plots available for vibration reduction testing. In 2-dimensional beam, the maximum deflections for Aluminium at 75 bar (0.41948E-02). But by increasing thickness by $1 \mathrm{~mm}$, deflection which is less compared to old as shown in fig 4.4. Also in 3-dimensional model, the maximum deflections for 
Aluminium at 75 bar $(0.16183 \mathrm{E}-04)$. But by increasing thickness by $1 \mathrm{~mm}$ deflection which is less compared to old as shown in fig 4.5 .

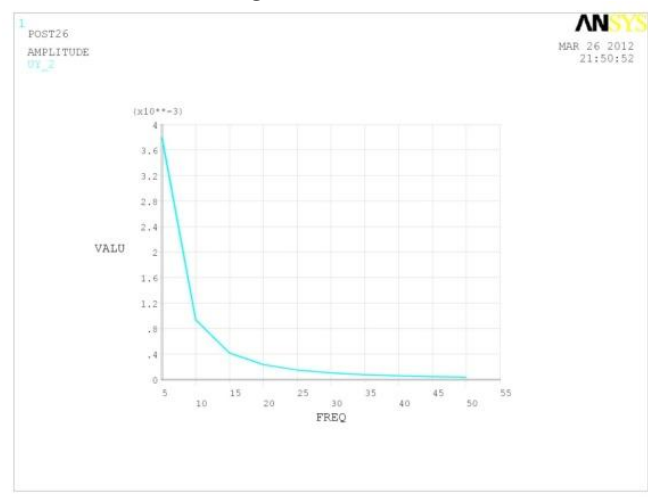

Fig 4.4: Reduction of vibration $2 \mathrm{D}$

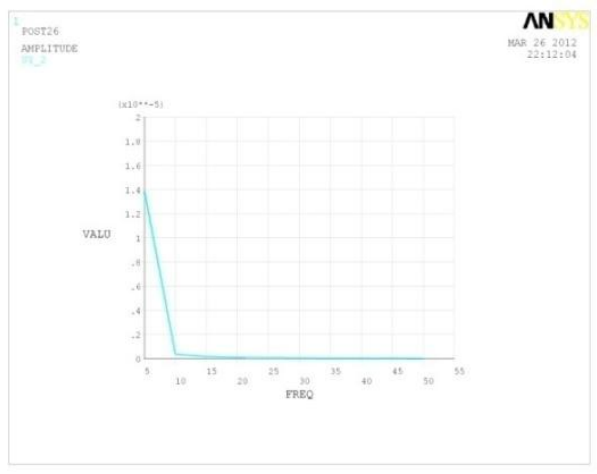

Fig 4.5: Reduction of vibration for 3D

\section{Conclusion}

In this work vibration analysis was carried out for 2-D and 3-D model along with different direction for HF 18 material at different nodes. The analysis was done on HF 18 material for compression testing in the range of 45-75 bar. It is observed that during under compression pressure the vibration and deflection characteristics were small at lower range of comp. pressure. Further in order to reduce vibration level, thickness of outer periphery of cylinder increased by $1 \mathrm{~mm}$. Better results were obtained i.e. the level vibration is found to be less for HF 18 material. Therefore it is observed that we can predict and understand vibration levels in a better way during engine operating conditions.

\section{References}

[1]. W.J.Griffiths and J.Skorecki [1964] "Some aspects of vibration of a single cylinder diesel engine", Journal of sound and vibration vol.1 (345-364)

[2]. $\quad$ S.D.Haddad and H.L.Pullen [1974], "Piston slap as source of noise and vibration in diesel engine", Journal of sound and vibration 34(2), (249-260).

[3]. L. Chabot PSA Peugeot Citroen, Oliver G.K. Yates Ricardo Group, "Noise and Vibration Optimization of a Gasoline Engine", Fifth Ricardo Software International User Conference in Detroit [2000].

[4]. H. Zheng, G.R. Liu, J.S. Tao, K.Y. Lam, "FEM/BEM analysis of diesel piston-slap induced ship hull vibration and underwater noise", ELSEVIER, Applied Acoustics 62 [2001] 341-358

[5]. S.H. Cho, S.T. Ahn And Y.H. Kim [2002], "A simple model to estimate the impact force induced by piston slap", Journal of Sound and vibration Vol. 255 (229-242).

[6]. Takayushi Aoyama, Sigeo Suzuki, Atasushi Kawamto, Takashi Noda, Toshihiro Ozasa, Takeyushi Kato, Takashi Ito "Preventive Design and Analysis of Cavitation Noise on Diesel Engine"[2004], R and D Review of Toyata CRDL Vol. 40 No.1 36-42.

[7]. Nobutaka TSUJIUCHI, Takayuki KOIZUMI, Shinya UEMURA Department of Engineering, Doshisha University, Japan[2006], "Modeling of Engine Block and Response Analysis of Piston Slap".

[8]. Anthony Deku, Subramanya Kompella, Department of Mechanical Engg., Blekinge, Sweedon, "Cavitation in Engine Cooling Fluid Due to Piston Cylinder Assembly Forces", ISRN : BTH-AMT-EX-[2006]/D-13—SE.

[9]. R.S.Khurmi and J.K.Gupta, "Machine Design", S.Chand Publication[page no.[1137].

[10]. Dr. Sadhu Singh, "Machine Design", Khanna Publication Table A.4, page no. 1126 and 1143.

[11]. VCR Engine Test set up, 1-cylinder, 4-strike, Diesel (Computerised), Kirloskar Oil Engine make, Instruction manual, Apex Innovations.

[12]. ANSYS Release 10 Documentation. 